\title{
LIFECOMP: EL MARCO DE REFERENCIA EUROPEO PARA LA COMPETENCIA PERSONAL, SOCIAL Y DE APRENDER A APRENDER. RELEVANCIA EN EL CONTEXTO DE LA COVID-19 ${ }^{1}$
}

\author{
Lifecomp: The european framework for the key competence \\ personal, social and learning to learn. Relevance in the \\ COVID-19 context
}

\author{
Marcelino Cabrera Giráldez \\ Investigador del Centro Común de Investigaciones de la Comisión Europea \\ Doctorando del Programa Unión Europea de la UNED \\ Arianna Sala \\ Investigadora del Centro Común de Investigaciones de la Comisión Europea
}

http://dx.doi.org/10.18543/ed-69(1)-2021pp155-186

Recibido: 29.05.2021

Aceptado: 18.06.2021

${ }^{1}$ Erratum/Errata: Tras la publicación en línea el 07/07/2021 (https://revista-estudios. revistas.deusto.es/issue/view/270) antes de la impresión definitiva del número 69 (1) de 2021 de la Revista, el autor de este estudio pidió a la Dirección de la Revista la inclusión de un segundo autor, concretamente el de Arianna Sala, a lo que la Dirección accedió tras las oportunas explicaciones el 13 de julio de 2021.

Erratum/Errata: After the online publication on 07/07/2021 (https://revista-estudios. revistas.deusto.es/issue/view/270) before the final printing of number 69 (1) of 2021 of the Journal, the author of this study asked the Editorial Team of the Journal to include a second author, Arianna Sala. The Editorial Team accepted the requested modification and it was made on July 13, 2021. 


\section{Resumen}

Respetando el principio de la subsidiariedad, la Unión Europea promueve las competencias clave para el aprendizaje permanente. Una de las ocho que enunció el Consejo Europeo en su Recomendación de 2018 sobre competencias clave es la competencia 'Personal, Social y de Aprender a aprender'. LifeComp es el marco conceptual europeo para esta competencia, que establece las tres áreas y las nueve subcompetencias que la componen: Autorregulación, Flexibilidad y Bienestar (Área personal); Empatía, Comunicación y Colaboración (Área social); Mentalidad de crecimiento, Pensamiento crítico y Gestión del aprendizaje (Aprender a aprender). El marco conceptual fue publicado en junio de 2020. Tener las competencias enunciadas por LifeComp se ha mostrado de particular relevancia en el contexto de la pandemia de la Covid-19. Describimos el marco y damos algunas indicaciones sobre su potencial para los ciudadanos tanto ahora como en la postpandemia.

\section{Palabras clave}

Competencias clave para el aprendizaje permanente, subsidiariedad europea, valores europeos, competencias personales, competencias sociales, pensamiento crítico, información falsa, desinformación, Covid-19.

\section{Abstract}

While respecting the subsidiarity principle, the European Union fosters the Key competencies for lifelong learning. One of the eight key competences proposed by the European Council in its Recommendation of 2018 on Key Competences is 'Personal, social and learning to learn'. LifeComp is the European conceptual framework for this competence. It establishes three areas and nine subcompetences: Self-regulation, Flexibility and Wellbeing (Personal area); Empathy, Communication and Collaboration (Social area); Growth mindset, Critical thinking and Managing learning (Learning to learn). The conceptual framework was released in June 2020. Having the LifeComp competences have proven to be relevant in the context of the Covid-19 pandemic. We describe the framework and provide indications on its potential for citizens now and in the post pandemic era.

\section{Keywords}

Key competences for lifelong learning, European subsidiarity, European values, Personal competences, Social competences, Critical thinking, Misinformation, Disinformation, Covid-19. 
SUMARIO: I. INTRODUCCIÓN: NORMATIVA EUROPEA. II. ¿QUÉ SON LAS COMPETENCIAS CLAVE PARA EL APRENDIZAJE PERMANENTE?. III. LA COMPETENCIA PERSONAL, SOCIAL Y DE APRENDER A APRENDER. IV. EL marco Conceptual LIFECOMP. 1. Área Personal. 2. Área social. 3. Aprender a aprender: el pensamiento crítico. V. CONCLUSIONES. VI. REFERENCIAS.

\section{INTRODUCCIÓN: NORMATIVA EUROPEA}

En 2006, el Parlamento Europeo y el Consejo de la Unión Europea adoptaron la Recomendación sobre Competencias clave para el aprendizaje permanente (Parlamento Europeo y Consejo Europeo 2006), revisándola en 2018 (Consejo de Europa 2018). La Recomendación establece un conjunto básico de habilidades necesarias para trabajar y vivir en el presente siglo, respetando el principio de subsidiariedad aplicable a algunas de las políticas europeas. La subsidiariedad dicta que la autoridad debe resolver los asuntos en las instancias más cercanas a los interesados. El principio se aplica a los sistemas y políticas de educación, que son competencia exclusiva de los Estados miembros y, en algunos de ellos, de las regiones (de las comunidades autónomas en el caso de España).

El objetivo de la Recomendación es que todos los ciudadanos tengan el conjunto de competencias necesarias para su desarrollo personal, la inclusión social, la ciudadanía activa y el trabajo. La Recomendación proporciona un marco general de referencia europea de utilidad para los diseñadores de políticas públicas, los sistemas de educación y formación, el personal docente, los empleadores, los servicios de empleo y los estudiantes, al tiempo que apoya las iniciativas en las escalas local, regional, nacional y europea para promover el desarrollo de tales competencias con una perspectiva de aprendizaje permanente.

Los Estados miembros de la Unión Europea pueden adoptar la Recomendación del Consejo, señalando éste su respeto pleno por los principios de subsidiariedad y proporcionalidad que se aplican al ámbito de la Educación. Las Recomendaciones son actos legislativos no vinculantes que permiten a las instituciones europeas dar a conocer sus puntos de vista y sugerir una línea de actuación sin imponer obligaciones legales a los Estados miembros. Esto significa que la Comisión ofrece pautas de implementación de las Recomendaciones, elaborando pautas de la manera más consensuada posible (por ejemplo, a través de consultas a expertos de los diferentes países e incluso de fuera de la Unión Europea).

Por un lado, las competencias clave necesarias para el desarrollo personal, la empleabilidad y la inclusión social se derivan de la evolución 
económica y social europea. Por otro, las diversas iniciativas implantadas en Europa durante la última década han sido un acicate importante. Tras los atentados terroristas de París, los Ministerios de Educación de los Estados miembros de la UE formularon la 'Declaración sobre la promoción de la ciudadanía y los valores comunes de libertad, tolerancia y no discriminación a través de la educación' (Ministros de Educación de la UE 2015), que reconoce la importancia de destacar, reconocer y promover los valores europeos a través de la educación formal, informal y no formal. Cada vez se presta mayor atención a la pertinencia de los valores comunes en el funcionamiento de nuestras sociedades. Así, el marco de referencia de competencias para una cultura democrática del Consejo de Europa presenta un conjunto exhaustivo de valores, capacidades y actitudes para una participación adecuada en las sociedades democráticas (Consejo de Europa 2018). De ahí que uno de los objetivos de la citada Recomendación sea reforzar la adquisición de competencias ciudadanas para concienciar sobre valores comunes, ya que forman la base del desarrollo personal y social.

Cabe decir que, si bien cada sociedad tiene un debate permanente sobre qué valores adoptar y promover, y que los países pueden tener diferentes enfoques para su enseñanza, la UE destaca la relevancia de sus valores fundamentales como motor clave de nuevas formas de escolarizar, aprender y relacionarse entre sí y con el entorno. Tales valores son los referidos en el Artículo 2 del Tratado de la Unión Europea (TUE) (UE 2012) y en la Carta de los Derechos Fundamentales de la Unión Europea (UE 2000): respeto de la dignidad humana, libertad, democracia, igualdad, Estado de derecho, respeto de los derechos humanos, incluidos los derechos de las personas pertenecientes a minorías, pluralismo, no discriminación, tolerancia, justicia, solidaridad e igualdad de género.

Por otro lado, el Pilar europeo de derechos sociales (Comisión Europea 2017) establece el principio de que toda persona tiene derecho a una educación, una formación y un aprendizaje permanente inclusivos y de calidad. El pilar europeo señala que para ello las personas deben mantener y adquirir capacidades que les permitan participar plenamente en la sociedad y gestionar las transiciones en el mercado laboral de manera exitosa, así como el derecho de toda persona a recibir asistencia personalizada oportuna y al aprendizaje permanente para mejorar su empleabilidad. Además, la promoción de las competencias clave constituye uno de los objetivos del Espacio Europeo de Educación ${ }^{2}$, que podría «aprovechar plenamente el potencial de la educación y la cultura como motor para la creación de empleo, la justicia

${ }^{2}$ Véase https://ec.europa.eu/education/education-in-the-eu/european-educationarea_es 
social y la ciudadanía activa, así como un medio de vivir la identidad europea en toda su diversidad» (Comisión Europea 2017).

\section{II. ¿QUÉ SON LAS COMPETENCIAS CLAVE PARA EL APRENDIZAJE PERMANENTE?}

La Comisión Europea define las competencias clave como una combinación de conocimientos, habilidades y actitudes (Comisión Europea 2018). El conocimiento se compondría de conceptos, hechos, datos, ideas y teorías que ya están establecidos y facilitan la comprensión de un área o tema determinado. Las habilidades se definen como la capacidad para llevar a cabo procesos y utilizar el conocimiento adquirido para lograr resultados. Las actitudes describen la disposición y la mentalidad necesarias para actuar o reaccionar ante las ideas, las personas o las situaciones. Para la Comisión Europea, las competencias clave se desarrollan a lo largo de la vida, mediante la educación formal, no formal e informal, y mediante el aprendizaje en diferentes entornos, incluidos la familia, la escuela, el lugar de trabajo, el vecindario y las diversas comunidades en las que participa el individuo. Todas las competencias clave se consideran igualmente importantes. Aspectos esenciales de unas apoyarán el desarrollo de otras, siendo transversales y complementarias. Por ejemplo, habilidades como el pensamiento crítico, la resolución de problemas, el trabajo en equipo, la comunicación, la creatividad, la capacidad de negociación, la capacidad analítica y las habilidades interculturales, están trasversalmente integradas en todas las competencias clave.

La Recomendación establece ocho competencias clave:

- Competencia en lectoescritura

- Competencia multilingüe

- Competencia matemática y competencia en ciencia, tecnología e ingeniería

- Competencia digital

- Competencia personal, social y de aprender a aprender

- Competencia ciudadana

- Competencia emprendedora, y

- Competencia en conciencia y expresión culturales.

Cada competencia necesita de un marco conceptual y una implementación adecuados, es decir, que tenga el consenso europeo y pueda ponerse en práctica en los sistemas de educación de los Estados miembros. En este artículo abundamos en el marco conceptual preparado por la Comisión Europea para la 'Competencia personal, social y de aprender a aprender' y elaboramos sobre la relevancia esta competencia, que se ha hecho palpable en el 
contexto de la actual crisis sanitaria y socioeconómica causada por el virus SARS-CoV-2. Otras competencias claves como la digital y la emprendedora también tienen sus propios marcos de referencia europeos ${ }^{3}$, mientras que una institución paneuropea, el Consejo de Europa, ha desarrollado un marco referencial para la 'Competencia ciudadana'.

Una educación orientada a las competencias se centra en los resultados de los procesos de aprendizaje, así como en el hecho de que el aprendizaje ocurre en una amplia gama de contextos. La educación orientada a las competencias se considera ventajosa en un momento en que la base de conocimientos de nuestras sociedades se está desarrollando aceleradamente y las habilidades necesarias deben transferirse y desarrollarse contextos sociales diversos (Comisión Europea 2018). Los ciudadanos europeos necesitan poseer unas competencias clave y unas habilidades básicas para su realización y su desarrollo personal, su empleabilidad, su inclusión social, y su participación cívica democrática. A lo largo del proceso de revisión de la Recomendación de 2006, se llevaron a cabo consultas, durante las cuales los educadores y expertos expresaron la urgente necesidad de considerar los aspectos del desarrollo personal y social en todos los niveles y sectores de la educación y la formación. Estos aspectos han recibo una variedad de nombres en estudios internacionales y marcos de competencias existentes, como 'habilidades del siglo XXI', 'habilidades para la vida', 'habilidades socioemocionales', 'habilidades blandas' (soft skills) o 'habilidades transversales'.

La adquisición de competencias tiene también por objeto sentar las bases para la consecución de unas sociedades más equitativas y democráticas, respondiendo a la necesidad de ir hacia un crecimiento integrador y sostenible, mantener la cohesión social y desarrollar la cultura democrática. Un aspecto transversal en casi todas ellas es la competencia en sostenibilidad y de lucha contra el cambio climático. La educación se convierte en una herramienta primordial para ello. Fomentar una educación para la sostenibilidad, bajo una perspectiva de aprendizaje constante, es una necesidad imperiosa ante la emergencia que vivimos y el incierto futuro de las jóvenes generaciones 5 .

3 Véase DigComp (https://ec.europa.eu/jrc/en/digcomp) y EntreComp (https://ec.europa.eu/social/main.jsp?catId=1317\&langId=en).

4 Véase https://rm.coe.int/libro-competencias-ciudadanas-consejo-europeo16-02-18/168078baed

5 Bianchi, G. y Cabrera Giraldez, M., 2021. Hacia un marco europeo de educación para la sostenibilidad. En preparación. 


\section{LA COMPETENCIA PERSONAL, SOCIAL Y DE APRENDER A APRENDER}

La automatización está cambiando el mercado laboral. Las tareas rutinarias y poco cualificadas las realizan cada vez más las máquinas, lo que hace que las habilidades se vuelvan obsoletas rápidamente. Estamos asistiendo a cambios rápidos en las formas de empleo, que suelen estar dominadas por la temporalidad (EPSC. Comision Europea 2019). Por otro lado, los empleadores buscan cada vez más a trabajadores flexibles y con disposición a formarse continuamente. Los cambios demográficos, debidos al envejecimiento de la población en la UE, ponen de relieve la necesidad de renovar esfuerzos para fomentar el bienestar personal y garantizar vidas más largas, pero también más satisfactorias, al tiempo que se fomenta el envejecimiento activo a través del uso de las tecnologías digitales (Cabrera, M. y Malanowski, N. (eds) 2009). Para hacer frente a situaciones complejas de la vida, los ciudadanos europeos deben desarrollar competencias que les permitan afrontar con éxito los retos que plantean las múltiples transiciones en su vida laboral, en su ámbito personal y en la sociedad. Las personas necesitan lidiar con la incertidumbre, reforzar su resiliencia y construir relaciones interpersonales exitosas.

La educación formal, no formal e informal ${ }^{6}$, puede contribuir a la adquisición de estas competencias. En la Recomendación revisada de 2018, el Consejo de la Unión Europea cambió la antigua competencia 'Aprender a aprender' de 2006, reconociendo la importancia del desarrollo personal y social. Fue entonces titulada Competencia clave 'Personal, social y para aprender a aprender', definiéndose como la capacidad de que una persona reflexione sobre sí misma, gestione eficazmente el tiempo y la información, trabaje con los demás de forma constructiva, permanezca resiliente y gestione los procesos de aprendizaje. Entre otras habilidades, las personas deben conocer sus estrategias de aprendizaje preferidas y saber cómo seguir aprendiendo y buscando oportunidades de educación, formación y

${ }^{6}$ La educación informal se ofrece de forma casual en la cotidianidad del día a día y no aparece el ámbito curricular ni en las instituciones educativas. Se recibe en lugares del ámbito cotidiano, profesionales y de relaciones sociales. La educación formal o reglada es intencionada y planificada. Es la que conocemos como enseñanza obligatoria, desde la educación infantil hasta el final de la educación secundaria, con diferentes grados de obligatoriedad según el sistema educativo de cada país. La educación no formal es intencionada y planificada, pero ocurre fuera del ámbito de la escolaridad obligatoria, como por ejemplo los cursos, normalmente opcionales, de formación de adultos en contextos extraescolares. En esta última categoría, los llamados MOOCs (Massive Online Open Courses), o cursos sobre materias específicas ofrecidas en Internet, están experimentando actualmente un auge considerable. 
carrera. La nueva definición enfatiza que esta competencia «incluye la capacidad de hacer frente a la incertidumbre y a la complejidad, aprender a aprender, apoyar el bienestar físico y emocional, mantener la salud física y mental y ser capaz de liderar un futuro consciente de la salud y con orientación a la vida, la empatía y la gestión de conflictos» (Comisión Europea 2018). La competencia está entretejida con las otras competencias clave y comprende conocimientos, habilidades y actitudes que todos los ciudadanos deben desarrollar para participar activamente en la sociedad y en la economía en un contexto de creciente importancia de las 'habilidades blandas' y de globalización.

Recordemos que, según las teorías clásicas del desarrollo sociocultural (Vygotsky, L. S. 1997), el aprendizaje ocurre a través del proceso de internalización derivado de las interacciones sociales. Debido a la interacción social y al andamiaje proporcionado por un 'otro más informado' (Abtahi, Y., Graven, M., y Lerman, S. 2017), el alumno puede expandir progresivamente su competencia y autonomía. Además, el desarrollo de los individuos se ve influido por su participación en múltiples sistemas en los que tienen lugar complejas interrelaciones (Bronfenbrenner, U. 1979). Esto nos lleva a subrayar la importancia, por un lado, de las interacciones con la familia, educadores, pares, etc., y, por otro, de la relevancia del contexto sociocultural.

La educación, al enseñar competencias personales y sociales, puede ser también un medio de realización y autosatisfacción (Donlevy, V., van Driel, B., Horeau McGrath, C. 2019). En la educación formal, se ha demostrado que los programas dedicados al desarrollo de competencias sociales y emocionales (por ejemplo, autorregulación, empatía, resolución de problemas, comunicación o colaboración) tienen efectos significativamente positivos tanto en los estudiantes como en el personal docente (Durlak, J. A. et al. 2011). La educación socioemocional contribuye a promover la salud mental, el rendimiento académico y la empleabilidad de los estudiantes, aumentando los comportamientos prosociales y reduciendo los disruptivos (Cefai, C., Bartolo P. A., Cavioni. V, Downes, P. 2018), de modo que los beneficios socioeconómicos derivados de estos programas superan sustancialmente sus costes (Belfield, C. et al. 2015).

Finalmente, cabe señalar que la enseñanza de la competencia a través de la educación puede contribuir a lograr la Meta 4.7 de los Objetivos de Desarrollo Sostenible de las Naciones Unidas: que «todos los estudiantes, para 2030, adquieran los conocimientos y habilidades necesarios para promover el desarrollo sostenible, incluyendo la educación para el desarrollo sostenible y estilos de vida sostenibles, los derechos humanos, la igualdad de género, la promoción de una cultura de paz y la no violencia, la ciudadanía global, el reconocimiento de la diversidad cultural, y la contribución de la cultura al desarrollo sostenible» (Naciones Unidas 2015). 
La pandemia de la Covid-19 ha afectado nuestros estilos de vida, obligándonos a hacer cambios importantes en la educación, en el trabajo y en las habilidades necesarias en muchas facetas de la vida. En la situación actual, es especialmente importante que las personas sean capaces de reflexionar sobre sus grados de competencia como ciudadanos y que desarrollen, en particular, sus competencias personales, sociales y de aprender a aprender. El objetivo es desplegar nuestro potencial, autorregular nuestras emociones, pensamientos y comportamientos, y afrontar la complejidad que vivimos como agentes sociales responsables y ciudadanos reflexivos y prósperos.

\section{IV.EL MARCO CONCEPTUAL LIFECOMP}

La Comisión Europea ha desarrollado un marco conceptual, denominado LifeComp (Sala, A., Punie, Y., Garkov, V. y Cabrera Giraldez, M. 2020), en el que se identifican los elementos que componen la Competencia clave Personal, social y de sprender a aprender. El objetivo final del marco es dar un conjunto consensuado de directrices para la implementación flexible de esta competencia en los planes de estudio, respetando el principio de subsidiariedad europeo bajo el que se encuadran las políticas de educación y el aprendizaje permanente. Es significativo destacar que, en el momento de la publicación de LifeComp, los ciudadanos de todo el mundo estaban experimentando un gran estrés debido a una pandemia que ha generado incertidumbres sin precedentes. Una repentina crisis de salud pública mundial está provocando niveles desconocidos de alarma e inseguridad. Las sociedades y economías europeas se están viendo afectadas hasta el punto de que las personas se ven obligadas a adoptar actitudes de prevención radicales, cambiando sus estilos de vida y limitando sus interacciones sociales, creándose una conciencia sobre la dimensión colectiva y global de la salud humana.

La crisis de la Covid-19 está poniendo en tela de juicio las competencias personales y sociales que hemos adquirido a lo largo de la vida. Para hacer frente a la disrupción, los ciudadanos europeos están intentando adaptarse urgentemente a nuevas formas de aprender, trabajar, relacionarse con los demás y afrontar los peligros de la información deshonesta o distorsionada. Los medios de comunicación, y específicamente las redes sociales digitales, son un poderoso vehículo de transmisión de lo que se suele denominar «noticias falsas», contribuyendo a la incertidumbre general, un sentimiento exacerbado en estos tiempos. LifeComp es un marco que puede ayudar a los estudiantes y ciudadanos a adoptar una actitud preventiva con respecto a su propia salud y la salud de los demás, a discernir la información confiable de la desinformación, a autorregular las emociones y a gestionar el aprendizaje de manera flexible. Junto con un futuro marco competencial en sostenibilidad, Life Comp puede ayudar a conservar la esperanza, especialmente de las 
generaciones jóvenes. LifeComp, de manera consensuada con numerosos expertos ${ }^{7}$, pretende establecer un lenguaje común las competencias personales y sociales necesarias en este contexto volátil, complejo e incierto. Veamos sus áreas y elementos.

Exponemos a continuación la tabla con las áreas y competencias de LifeComp. Describimos más adelante las correspondientes a las áreas de desarrollo personal y social. La estructura de LifeComp se corresponde con las tres áreas de la competencia clave (Social, Personal y Aprender a aprender). Los tres descriptores de cada una de las nuevas competencias que componen el marco siguen una lógica Concienciación, Comprensión y Acción (Awareness, Understanding, Action). LifeComp propone como metáfora un árbol, que enfatiza la interdependencia dinámica de todas las competencias en un individuo y un modelo de crecimiento en el tiempo. En las raíces se representa la conexión del individuo con el contexto sociocultural y con los demás, sugiriendo que todas las partes del árbol crecen simultáneamente y son igualmente necesarias su desarrollo como ser vivo.

${ }^{7}$ Las consultas con estos expertos han sido numerosas y acompañadas de revisiones de la literatura. Véase la lista exhaustiva en la publicación de Sala et al. (2020). 
Tabla 1. LifeComp: El marco de referencia europeo para la 'Competencia clave personal, social y de aprender a aprender'

\begin{tabular}{|c|c|c|}
\hline Área & Competencia & Descriptor \\
\hline \multirow[t]{3}{*}{$\begin{array}{l}\text { Área } \\
\text { personal }\end{array}$} & $\begin{array}{l}\text { Autorregulación } \\
\text { Conciencia y } \\
\text { gestión de las } \\
\text { emociones, el } \\
\text { pensamiento y el } \\
\text { comportamiento }\end{array}$ & $\begin{array}{l}\text { - Conciencia y expresión de las emociones, } \\
\text { los pensamientos, los valores y los } \\
\text { comportamientos individuales } \\
\text { - Comprender y regular las emociones, } \\
\text { pensamientos y comportamientos } \\
\text { individuales, así como las respuestas al } \\
\text { estrés. } \\
\text { - Fomentar el optimismo, la esperanza, la } \\
\text { resiliencia, la autoeficacia y un sentido del } \\
\text { propósito en la vida de cara al aprendizaje y } \\
\text { la acción }\end{array}$ \\
\hline & $\begin{array}{l}\text { Flexibilidad } \\
\text { Capacidad para } \\
\text { gestionar las } \\
\text { transiciones y la } \\
\text { incertidumbre y } \\
\text { afrontar los } \\
\text { desafíos. }\end{array}$ & $\begin{array}{l}\text { - Disponibilidad para revisar las opiniones y } \\
\text { la acción ante nuevas evidencias } \\
\text { - Comprender y adoptar ideas novedosas, } \\
\text { enfoques, herramientas y de actuar en } \\
\text { contextos cambiantes } \\
\text { - Gestionar las transiciones en la vida, la } \\
\text { participación social, el trabajo y las formas } \\
\text { de aprender, al tiempo que se toman } \\
\text { decisiones conscientes y se establecen } \\
\text { objetivos }\end{array}$ \\
\hline & $\begin{array}{l}\text { Bienestar } \\
\text { Búsqueda de la } \\
\text { satisfacción con la } \\
\text { vida, cuidado de la } \\
\text { salud física, mental } \\
\text { y social; y } \\
\text { adopción de un } \\
\text { estilo de vida } \\
\text { sostenible }\end{array}$ & $\begin{array}{l}\text { - Conciencia de que el comportamiento } \\
\text { individual, las características personales y } \\
\text { los factores sociales y ambientales influyen } \\
\text { en la salud y el bienestar8. } \\
\text { - Comprender los riesgos potenciales para el } \\
\text { bienestar y utilizar información y servicios } \\
\text { fiables para la salud y la protección social. } \\
\text { - Adopción de un estilo de vida sostenible que } \\
\text { respete el medio ambiente y el bienestar } \\
\text { físico y mental propio y de los demás, } \\
\text { mientras busca y ofrece apoyo social. }\end{array}$ \\
\hline
\end{tabular}

${ }^{8}$ La relevancia de esta competencia se ha hecho extraordinariamente palpable con la crisis sanitaria de la Covid-19. 


\begin{tabular}{|c|c|c|}
\hline Área & Competencia & Descriptor \\
\hline \multirow[t]{3}{*}{$\begin{array}{l}\text { Área } \\
\text { social }\end{array}$} & $\begin{array}{l}\text { Empatía } \\
\text { La comprensión de } \\
\text { las emociones, } \\
\text { experiencias y } \\
\text { valores de otra } \\
\text { persona, y las } \\
\text { respuestas } \\
\text { apropiadas. }\end{array}$ & $\begin{array}{l}\text { - Conciencia de las emociones, experiencias y } \\
\text { valores de otra persona. } \\
\text { - Comprender las emociones y experiencias de } \\
\text { otra persona y la capacidad de adoptar su } \\
\text { perspectiva. } \\
\text { - Capacidad de respuesta a las emociones y } \\
\text { experiencias de otra persona, siendo } \\
\text { consciente de que la pertenencia al grupo } \\
\text { propio influye en la actitud. }\end{array}$ \\
\hline & $\begin{array}{l}\text { Comunicación } \\
\text { Uso de estrategias } \\
\text { de comunicación y } \\
\text { códigos específicos } \\
\text { según el contexto y } \\
\text { el contenido. }\end{array}$ & $\begin{array}{l}\text { - Conciencia de la necesidad de una variedad } \\
\text { de estrategias de comunicación, registros de } \\
\text { lenguaje y herramientas que se adapten al } \\
\text { contexto y al contenido. } \\
\text { - Comprender y gestionar interacciones y } \\
\text { conversaciones en diferentes contextos } \\
\text { socioculturales y situaciones específicas de } \\
\text { dominio. } \\
\text { - Escuchar a los demás y entablar } \\
\text { conversaciones con confianza, asertividad, } \\
\text { claridad y reciprocidad, tanto en contextos } \\
\text { personales como sociales. }\end{array}$ \\
\hline & $\begin{array}{l}\text { Colaboración } \\
\text { Participación en } \\
\text { actividades } \\
\text { grupales y trabajo } \\
\text { en equipo } \\
\text { reconociendo el } \\
\text { trabajo de los } \\
\text { demás y } \\
\text { respetándolos }\end{array}$ & $\begin{array}{l}\text { - Intención de contribuir al bien común con } \\
\text { conciencia de que otros pueden tener } \\
\text { diferentes afiliaciones culturales, } \\
\text { antecedentes, creencias, valores, opiniones o } \\
\text { circunstancias personales. } \\
\text { - Comprender la importancia de la confianza, } \\
\text { el respeto por la dignidad humana y la } \\
\text { igualdad, afrontar los conflictos y negociar } \\
\text { los desacuerdos para construir y mantener } \\
\text { relaciones justas y respetuosas. } \\
\text { - Distribución justa de las tareas, los recursos } \\
\text { y las responsabilidades dentro de un grupo } \\
\text { teniendo en cuenta su objetivo específico; } \\
\text { reconocer los diferentes puntos de vista y } \\
\text { adoptar un enfoque sistémico. }\end{array}$ \\
\hline
\end{tabular}




\begin{tabular}{|c|c|c|}
\hline Área & Competencia & Descriptor \\
\hline \multirow[t]{3}{*}{$\begin{array}{l}\text { Aprender } \\
\text { a } \\
\text { Aprender }\end{array}$} & $\begin{array}{l}\text { Mentalidad de } \\
\text { crecimiento } \\
\text { Creer en el } \\
\text { potencial propio y } \\
\text { de los demás para } \\
\text { aprender y } \\
\text { progresar } \\
\text { continuamente }\end{array}$ & $\begin{array}{l}\text { - Conciencia de y confianza en las habilidades } \\
\text { propias y de los demás para aprender, } \\
\text { mejorar y conseguir objetivos con trabajo y } \\
\text { dedicación. } \\
\text { - Entender que el aprendizaje es un proceso de } \\
\text { toda la vida que requiere apertura, curiosidad } \\
\text { y determinación. } \\
\text { - Reflexionar sobre los comentarios de otras } \\
\text { personas, así como sobre las experiencias } \\
\text { exitosas y fallidas, para continuar } \\
\text { desarrollando el potencial propio. }\end{array}$ \\
\hline & $\begin{array}{l}\text { Pensamiento } \\
\text { crítico } \\
\text { Evaluación de la } \\
\text { información y los } \\
\text { argumentos que se } \\
\text { nos presenten para } \\
\text { llegar a } \\
\text { conclusiones } \\
\text { razonadas y } \\
\text { desarrollar } \\
\text { soluciones } \\
\text { innovadoras }\end{array}$ & $\begin{array}{l}\text { - Conciencia de los posibles sesgos en los } \\
\text { datos y las limitaciones personales cuando se } \\
\text { recopila información e ideas válidas y fiables } \\
\text { de diferentes fuentes acreditadas. } \\
\text { - Comparar, analizar, evaluar y sintetizar } \\
\text { datos, información, ideas y mensajes de los } \\
\text { medios de comunicación para sacar } \\
\text { conclusiones lógicas. } \\
\text { - Desarrollar ideas creativas, sintetizar y } \\
\text { combinar conceptos e información de } \\
\text { diferentes fuentes con el fin de resolver } \\
\text { problemas. }\end{array}$ \\
\hline & $\begin{array}{l}\text { Gestión del } \\
\text { aprendizaje } \\
\text { Planificación, } \\
\text { organización, } \\
\text { seguimiento y } \\
\text { revisión del propio } \\
\text { aprendizaje }\end{array}$ & $\begin{array}{l}\text { - Conciencia de los intereses de aprendizaje, } \\
\text { procesos y estrategias de nuestra elección, } \\
\text { así como de las necesidades de aprendizaje y } \\
\text { el apoyo requerido } \\
\text { - Planificación e implementación de los } \\
\text { objetivos, las estrategias, los recursos y los } \\
\text { procesos de aprendizaje } \\
\text { - Reflexionar y evaluar los propósitos, } \\
\text { procesos y resultados del aprendizaje, } \\
\text { estableciendo relaciones entre las diversas } \\
\text { áreas del conocimiento }\end{array}$ \\
\hline
\end{tabular}

Fuente: Sala, A., Punie, Y., Garkov, V. and Cabrera Giraldez, M., LifeComp: The European Framework for Personal, Social and Learning to Learn Key Competence

\section{1. Área Personal}

Se refiere al desarrollo personal, a prosperar y desplegar el potencial de cada individuo. Jacques Delors afirmaba que uno de los cuatro pilares de la 
educación para el aprendizaje permanente era 'aprender a ser', refiriéndose al desarrollo de «la propia personalidad y a poder actuar con creciente autonomía, juicio y responsabilidad personal» (Delors, J. 1996). Ser personalmente competente está estrechamente relacionado con 'aprender a ser', ya que cada individuo debe adquirir una serie de habilidades, conocimientos y actitudes, como se indica en la Recomendación del Consejo de 2018. 'Aprender a ser' implica tener conocimientos sobre como tener una mente, un cuerpo y un estilo de vida saludables, tener la habilidad de hacer frente a la complejidad, la incertidumbre y el estrés, buscar apoyo cuando sea necesario y mantenerse resistente, así como desarrollar la capacidad de trabajar de forma autónoma y gestionar la carrera profesional. También implica tener actitudes de asertividad, integridad, automotivación, resolución de problemas para enfrentar los cambios y una disposición positiva hacia la promoción del bienestar personal, social y físico. Debe reconocerse la influencia de los factores contextuales socioculturales para promover u obstaculizar el alcance de la 'agenciación humana", así como la necesidad de políticas para abordar las causas estructurales de las desigualdades y promover el florecimiento de todas las personas. La educación para el desarrollo personal tiene el potencial de aliviar la desigualdad, ofreciendo a todos los ciudadanos las herramientas para analizar el mundo y actuar críticamente (EPSC, European Commission 2017). En esta área de LifeComp se encuentran las competencias de Autorregulación, Flexibilidad y Bienestar.

\section{a Autorregulación}

La autorregulación es una capacidad que nos permite alterar y regular nuestras respuestas para que no sean el resultado de una reacción inconsciente a un estímulo (Baumeister, R. F. y Heatherton, T. F. 1996). La autorregulación es un proceso cíclico que se lleva a cabo a través de tres pasos principales: establecer un estado deseado, es decir, crear planes de acción, establecer metas y anticipar resultados futuros; comparar el estado actual con el deseado, monitorearse y cultivar la autoconciencia; y actuar para modificar el estado actual si no corresponde al deseado (Moilanen, K. L. 2007). La fuerza autorreguladora aumenta con la práctica. Las situaciones estresantes hacen que sea más difícil continuar luchando contra la frustración y controlar con éxito las respuestas impulsivas, lo cual contribuye al sentido de agenciación personal, es decir, la valoración de nuestra capacidad de actuar sobre

${ }^{9}$ La 'agenciación humana' ('human agency') es la capacidad de ejercitar el control sobre nuestro propio funcionamiento y sobre los eventos que afectan nuestra vida. Fue el psicólogo Bandura (2001) quien la introdujo y se usa comúnmente en el léxico relacionado con las competencias. 
uno mismo y el medio ambiente (Bandura, A. 2017). La autorregulación juega un papel importante en la participación activa en el proceso de aprendizaje y, junto con la autoeficacia o creencia en la capacidad de la persona para lograr sus objetivos, es un componente clave de la competencia de emprendimiento, es decir, la capacidad de crear valor cultural, social o económico (Bacigalupo, M., Kampylis, P., Punie, Y., y Van den Brande, G. 2016). Los individuos necesitan poder percibir y reconocer sus propias emociones y pensamientos, sus respuestas corporales, los valores que los impulsan hacia el desarrollo personal, y cómo esos factores influyen en su comportamiento y afectan a su desempeño en diversas áreas de la vida.

En el contexto de la Covid-19, el grado de autorregulación que han tenido los individuos ha sido determinante para poder seguir trabajando, estudiando y mantener la salud física y mental. Desafortunadamente, una parte de la población no ha sabido autorregularse, manifestando descontrol ante impulsos destructivos que han ido desde pérdida de concentración para trabajar y estudiar hasta la violencia doméstica y los comportamientos autolíticos, por citar algunos efectos. Todas las emociones, ya sean las que provocan sentimientos positivos (emociones positivas) o las que provocan sentimientos negativos (emociones negativas), son mecanismos adaptativos necesarios para la vida. Al mismo tiempo, el despliegue de estrategias para prestar atención y regular las emociones ayuda a las personas a actuar mejor en el ámbito personal, educativo y profesional (Koole, S. 2009).

Estas estrategias pueden ser tanto la reducción intencional de la intensidad de las emociones que causan sentimientos negativos como el aumento de las emociones positivas. Fomentar el optimismo, la esperanza, la resiliencia, la autoeficacia y un sentido de propósito, parte del descriptor de esta competencia, ha sido difícil durante la pandemia, especialmente de los más jóvenes y sus familias. De ahí la necesidad crucial de buscar una perspectiva positiva de la vida y un sentido de propósito, centrándonos en cultivar la esperanza, el optimismo, la resiliencia y la autoeficacia (Luthans, F., Avolio, B., Avey, J. B., y Norman, S. M. 2007) y de conservar la capacidad de imaginar y recorrer formas alternativas para alcanzar las metas, como una suerte de «plan $B »$.

\section{b Flexibilidad}

De acuerdo con LifeComp, ser flexible significa tener la capacidad de adaptarse a nuevas situaciones y hacer ajustes para adaptarse a los cambios. Es la competencia más solicitada en los anuncios de empleo de 2019, ya que los empleadores buscan cada vez más personas con la capacidad de modificar la actitud o el comportamiento para adaptarse a las modificaciones en el lugar de trabajo (CEDEFOP 2019). Al ser el contexto global contemporáneo cada vez más volátil, incierto, complejo y ambiguo, lo que se ha llamado 
paradigma VUCA (volatile, uncetain, complex, ambiguous) (Bennett, N., y Lemoine, G. J. 2014), los ciudadanos deben poder cambiar o persistir en sus comportamientos para hacer frente a circunstancias internas y externas en constante cambio. En la descripción de flexibilidad, se enfatiza la relevancia de ser consciente de los datos disponibles y de las circunstancias cambiantes, mostrando rápidamente la voluntad de modificar las acciones, las opiniones o la forma habitual de obrar. Abarca el interés intelectual y la curiosidad por explorar nuevas situaciones, así como la capacidad de considerar múltiples aspectos de un tema específico y de comprender, negociar y sopesar diferentes puntos de vista. Ser flexible implica igualmente que las personas puedan reflexionar y reaccionar adecuadamente a la retroalimentación positiva y negativa y a modificar los planes personales cuando sea necesario. Destacamos que la flexibilidad se centra en la relevancia de adoptar una actitud de apertura a nuevas ideas, herramientas o formas de hacer las cosas, así como la capacidad de lidiar con la incertidumbre. Los individuos deben estar abiertos a generar soluciones alternativas, y a abandonar las estrategias que no conducen al resultado deseado, frenando la tendencia a continuar un curso inicial de acción en situaciones que requieren un cambio (Cañas, J. J., Quesada, J. F., Antolí, A. y Fajardo, I. 2003).

Nuestra era digital es intrínsecamente compleja. Las nuevas herramientas digitales, la inteligencia artificial (IA), la realidad virtual (VR), y los grandes datos (big data), se están haciendo omnipresentes en casi todas las áreas importantes de la vida, como la educación, el trabajo y la investigación. Por ello, ser flexible en la sociedad actual significa también poder mejorar nuestras competencias digitales. La flexibilidad abarca las habilidades de gestión de carrera, la búsqueda continua de capacitación adicional para adaptarse a diferentes contextos laborales a cualquier edad, el establecimiento de objetivos significativos y la toma de decisiones profesionales efectivas hacia transiciones exitosas (European Lifelong Guidance Policy Network 2015). Los individuos necesitan adquirir la capacidad de visualizar de forma proactiva opciones futuras y utilizar estrategias relevantes para tomar decisiones informadas, afrontando la indecisión y la ansiedad que se pueden experimentar al tomar una decisión (Camara, W., O’Connor, R., Mattern, K., y Hanson, M. A. 2015).

La pandemia de la Covid-19 ha dejado un mundo de extraordinaria incertidumbre, en el que la flexibilidad de los individuos se ha puesto a prueba de manera quizás sólo semejante a una situación de guerra. Uno de los hechos notables ha sido la necesidad perentoria de tener competencias digitales para trabajar y estudiar, habiéndose constatado la divisoria entre los que la tienen (y tienen la infraestructura digital) y los que no. En las escuelas, profesores y padres, además de los estudiantes, probablemente los más versátiles, se han tenido que adaptar a la nueva forma de educación online a marchas forzadas. 
Es fácil entender que los que no tenían un grado de destreza digital se han quedado excluidos o están en riesgo de exclusión. Si bien el presente de la demanda empleo se caracteriza por la flexibilidad, el futuro tras la pandemia se presenta radicalmente incierto, con una economía que se tendrá que basar en otro paradigma de producción más allá del basado en el consumo desmedido de recursos a base de poner el peligro el planeta y su biodiversidad, cuya pérdida es fuente probable de zoonosis como la del SARS-CoV-2.

\section{c Bienestar}

Lifecomp destaca la interconexión e interdependencia de las dimensiones física, mental, social y ambiental del bienestar, en línea la OMS, proponiendo adoptar una comprensión sistémica que tenga en cuenta la interacción de éstas. El bienestar puede caracterizarse como el resultado de la integración dinámica y de las relaciones entre ellos. Las personas pueden mejorar su bienestar físico, por ejemplo, teniendo una buena higiene del sueño, realizando ejercicios físicos adaptados a su condición y edad, y adoptando hábitos alimenticios saludables. El bienestar cognitivo puede mejorarse estimulando actividades creativas, cultivando la flexibilidad mental, la curiosidad y el placer de seguir aprendiendo toda la vida. El bienestar emocional puede fomentarse mediante el desarrollo de la autonomía, la comprensión y la regulación de las emociones, los pensamientos y los comportamientos, y fomentando la autoestima y el optimismo. Vemos que bienestar y autorregulación están estrechamente relacionados. Los individuos pueden aumentar también su bienestar social cultivando la empatía, cuidando de los demás y adoptando comportamientos altruistas, construyendo relaciones afectivas interpersonales, buscando ayuda cuando la necesitan y ofreciendo su apoyo a personas necesitadas. Los ciudadanos también pueden fomentar su bienestar existencial cultivando un sentido de propósito en la vida, tomando decisiones conscientes y buscando un equilibrio entre el trabajo y la vida personal. El bienestar ambiental también forma parte del bienestar personal. Puede promoverse adoptando un estilo de vida sostenible, reduciendo responsablemente nuestro impacto ambiental y abogando por acciones para combatir el cambio climático.

La pandemia de la Covid-19 y las acciones tomadas para combatir su propagación están realzando la interconexión entre el comportamiento de salud individual y la salud y el bienestar colectivos en todos los niveles, desde el local hasta el global. Ser responsables de nuestra salud, tomando medidas higiénicas y preventivas, repercute en la salud de los demás y viceversa. Para superar este desafío es vital que fortalezcamos nuestro sentido de responsabilidad compartida y de pertenencia a una comunidad más amplia. Al proteger nuestra propia salud, protegemos la de los demás. Al vacunarnos, lo hacemos 
por nuestra salud y por la salud de los otros. Más que nunca, los ciudadanos deben ser conscientes de su interdependencia global. Las vacunas son necesarias a escala global. Al ser la pandemia global por definición, todos los seres humanos deberían estar vacunados, so pena de que el problema persista. Los movimientos de solidaridad (véase la creación del fondo COVAX para la distribución de las vacunas en países en vías de desarrollo, o los debates recientes sobre la conveniencia de suprimir las patentes de las vacunas desarrolladas con fondos públicos), se corresponden esta idea de interdependencia.

Por otro lado, y también relevante para la situación de la Covid-19, la competencia en bienestar requiere la capacidad de acceder, comprender, evaluar y aplicar información de salud veraz para nuestras decisiones, bien sea sobre la prevención de enfermedades, sobre la asistencia sanitaria, o sobre la promoción de nuestra salud. Esta competencia está estrechamente relacionada con el área de Aprender a aprender, ya que la complejidad de nuestros sistemas de salud requiere una actitud de aprendizaje permanente para actualizar nuestros conocimientos y habilidades en salud necesarios para poder tomar decisiones informadas. En particular, tener un pensamiento crítico es precioso para poder distinguir la información de salud confiable de la no confiable. Los ciudadanos necesitan comprender los peligros de compartir información falsa sobre la salud, ya que estas informaciones pueden publicitar terapias nocivas o causar alarma. En el contexto que nos ocupa, hemos visto como la desinformación y las noticias falsas han causado un daño inusitado en los ciudadanos, que incluso pueden dudar de la conveniencia de vacunarse.

La pandemia nos llega en la 'era de la posverdad', en la que los hechos objetivos influyen menos en la opinión pública que las emociones y las creencias personales ${ }^{10}$, al tiempo que la desinformación erosiona la confianza de los ciudadanos en las instituciones y en los medios de comunicación y perjudica a nuestras democracias. A menudo, la desinformación respalda ideas radicales y extremistas, menoscabando la libertad de expresión, un derecho fundamental consagrado en la Carta de los Derechos Fundamentales de la Unión Europea (UE 2000), que comprende el respeto por la libertad y el pluralismo de los medios de comunicación, así como el derecho de los ciudadanos a opinar, recibir y transmitir información e ideas «sin injerencia de autoridades públicas y sin consideración de fronteras» (Comisión Europea, 2018). Según LifeComp, es crucial que los ciudadanos sean capaces de distinguir entre hechos reales, propaganda, opiniones y rumores. Las teorías conspirativas sobre el origen del virus, su propagación o supuestos remedios, surgen de círculos acientíficos. La Organización Mundial para la Salud (OMS), señala que la pandemia ha venido acompañada de una infodemia

${ }^{10}$ Oxford Learner's Dictionaries, 2016 
(infodemics) $)^{11}$. Las instituciones europeas y organismos globales han aunado esfuerzos en 2020 para combatir la desinformación y las teorías conspirativas en tiempos de Covid-19 (Comisión Europea y Alto Representante de la Unión Europea para Asuntos Exteriores y Política de Seguridad Común 2020).

\section{2. Área social}

Para LifeComp, el área social está relacionada con aprender a convivir y con la conciencia de la naturaleza social del ser humano. No referimos a la capacidad y a la voluntad de interactuar, comunicarse y colaborar con otros de manera constructiva. Según un informe prospectivo de la Comisión Europea, la mayoría de los trabajos emergentes de aquí a 2025 requerirán fuertes habilidades de colaboración y comunicación (Gonzalez Vazquez, I. et al., 2019). Junto con la empatía, el espíritu empresarial, la innovación y otras habilidades, la colaboración y la comunicación serán fundamentales para llegar a estar 'a prueba de robots' (Aoun, J. 2017) en un mercado laboral profundamente moldeado por los avances tecnológicos. Para ser socialmente competente, cada individuo debe adquirir una variedad de habilidades, conocimientos y actitudes, refiriéndose la competencia social, al conocimiento sobre los códigos de conducta y las reglas de comunicación aceptadas en nuestras sociedades, y a las habilidades que permiten al individuo comunicarse de manera constructiva en diferentes entornos, a trabajar en colaboración, negociar, mostrar tolerancia, expresar y comprender diferentes puntos de vista, generar confianza y sentir empatía (Sala, A., Punie, Y., Garkov, V. y Cabrera Giraldez, M. 2020). Ser socialmente competente significa también cultivar una actitud de colaboración, respetar la diversidad humana, superar los prejuicios y participar en la sociedad. Las competencias descritas en el área social están estrechamente entrelazadas con las competencias clave de «Ciudadanía» y «Conciencia cultural» de la Recomendación del Consejo, que complementan la descripción de las habilidades necesarias para vivir y prosperar juntos en nuestras sociedades democráticas (Consejo de Europa 2018).

\section{a Empatía}

La empatía se encuentra en todos los comportamientos prosociales y proporciona una base para afrontar el estrés y resolver conflictos (Kremer, J., y

${ }^{11}$ La OMS acuñó el término para referirse a la información excesiva sobre un determinado problema, lo que dificulta identificar la solución y dar una respuesta de salud pública. Véase: https://www.who.int/health-topics/infodemic\#tab=tab_1 
Dietzen, L. 1991). Habitualmente se habla de tres aspectos de la empatía: la capacidad de reconocer emociones en los demás; tomar cognitivamente la perspectiva de los demás y compartir estados emocionales con ellos; y la capacidad de ofrecer una respuesta adecuada a las emociones de los otros (Derntl, B. y Regenbogen, C. 2014). LifeComp cita diversos autores que señalan que la evidencia psicobiológica muestra que los cerebros humanos están programados para la empatía y que la capacidad de comprender y ayudar a los demás ha sido clave para la supervivencia de nuestra especie. También se sabe que la empatía se puede mejorar mediante el entrenamiento (Cavallini, E. et al. 2015), quizás con la excepción de personas que sufren algunos trastornos psicopatológicos en los que la empatía es mínima o está ausente.

Tener empatía conlleva la capacidad de ser consciente de las emociones y los valores de otras personas, estando estrechamente vinculada con la autorregulación. Cuanto más consciente seamos de nuestras propias emociones, mejor podremos reconocer los sentimientos de los demás. De manera no verbal, somos capaces de identificar con precisión al menos seis emociones básicas en los demás independientemente de nuestro origen cultural: ira, disgusto, miedo, felicidad, tristeza y sorpresa (Ekman, P., Sorenson, E. y Friesen, W. 1969). La capacidad de leer señales no verbales como el tono de voz, los gestos y las expresiones faciales son claves para la empatía. En el ámbito digital, también se utilizan señales no verbales para hacer más explícitas las emociones, como los emoticonos, lo cual es un reflejo de la necesidad humana de usar canales de comunicación no verbal. La empatía implica, además, la conciencia de la diversidad, la capacidad de reconocer y aceptar que personas de diferentes culturas pueden tener diferentes valores o experiencias, lo cual es parte de la riqueza de la humanidad. Cabe señalar que la habilidad de adoptar la perspectiva de las personas no implica necesariamente estar de acuerdo, siendo posible empatizar con alguien que tiene actitudes o valores diferentes de los nuestros.

En LifeComp se explicita que el entrenamiento de la propia autoconciencia y la autoempatía mejora la capacidad de comprender y reduce la angustia personal cuando nos confrontamos a los sentimientos de los demás. Así, la preocupación empática puede conducir a un comportamiento prosocial compasivo destinado a mitigar el sufrimiento de los demás. De manera importante, LifeComp señala que los comportamientos prosociales son intencionales y que varios factores interconectados median en la posible decisión de adoptarlos. Los individuos tienden a tener más empatía por otros que se ven o actúan como ellos o por aquellos que han tenido un sufrimiento parecido. Además, se suele ser más empático con los miembros del endogrupo. Por el contrario, puede producirse un fracaso empático hacia los miembros del exogrupo, que incluso puede dar lugar a conductas 
contraempáticas. La empatía cognitiva - que puede ser enseñada - puede desempeñar un papel cuando existe una falta de empatía emocional debido a diferencias raciales, étnicas, religiosas o físicas (Riess, H. 2017).

En el contexto pandémico, las conductas prosociales ha sido determinantes en casos de ayuda a los demás. Las expresiones de solidaridad (banco de alimentos, asistencia a mayores y enfermos en sus casas, ayudas entre familiares...) han sido y siguen siendo de gran relevancia en nuestras sociedades del bienestar, confrontadas al difícil acceso a la sanidad en tiempos en los que la protección ante el virus ha primado sobre el tratamiento de patologías habituales. El rol de los sanitarios ha sido crucial para mantener a flote los sistemas de salud ante las presiones causadas por los numerosos ingresos de enfermos de Covid-19. Las prácticas de solidaridad individual durante la pandemia han incluido varias formas de ayuda mutua. Estas formas de comportamiento han sido institucionalizadas a través de asociaciones de vecinos. El cumplimiento de las normas que limitan la libertad personal también se ha descrito como una forma de empatía en la medida en que ha implicado la exigencia de un sacrificio por parte de algunos para beneficiar a otros evitando participar en actividades susceptibles de propagar la infección, poniendo en particular riesgo a los miembros más vulnerables de la comunidad, como las personas mayores, las personas con comorbilidades, los trabajadores esenciales o las personas que no pueden aislarse porque simplemente no tienen cómo (personas sin hogar).

Relacionado con la contraempatía, podemos encontrar el rechazo a vacunarse, con la creencia de algunos individuos de que al estar otros vacunados, se creará la igualmente la inmunidad colectiva sin que el individuo se tenga que arriesgar ('efecto polizón'). La competencia de pensamiento crítico, o más bien su carencia, se encuentra directamente relacionada con estas actitudes. Por el contrario, recibir una vacuna con la motivación de reducir el riesgo de otros, más vulnerables, podría entenderse como un acto empático y solidario, como también puede serlo no saltarse la cola de la vacunación.

\section{b Comunicación}

Cuando participamos en una interacción interpersonal, cada comportamiento tiene un significado (Watzlawick, P., Helmick Beavin, J. y Jackson, D. 1967).. Sin embargo, comunicar con eficacia y asertividad parece algo complicado para el ser humano. El código de comunicación debe ser comprensible tanto por el remitente como por el receptor del mensaje para ser interpretado correctamente, mientras que el canal de comunicación conecta al emisor y al receptor física y psicológicamente, permitiendo que se produzca la comunicación. Ejemplos de canales de comunicación actuales escritos son el correo electrónico o los mensajes de texto. En las últimas décadas, 
estos nuevos canales de comunicación han cobrado importancia y popularidad.

Se puede decir que las tecnologías digitales han creado nuevas formas de comunicación. La comunicación mediada por ordenador (computer mediated communication, $C M C$ ) permite la comunicación y la colaboración a distancia, lo que hace que las personas puedan intercambiar mensajes y grandes cantidades de datos de forma instantánea y a bajo coste, lo que facilita la conexión en casos en los que no se puede hacer cara a cara. Las plataformas de redes sociales se utilizan masivamente para conectarse con otros, mantener relaciones y obtener información. Sin embargo, la falta de señales socioemocionales y no verbales de la $\mathrm{CMC}$, que están presentes en la comunicación cara a cara, puede afectar la efectividad de la comunicación, dando lugar a interpretaciones equívocas o indeseadas. La falta de contacto inmediato con los demás puede favorecer la polarización ideológica y política y desinhibirnos, dando lugar a comportamientos verbales agresivos (Rösner, L. y Krämer, N. 2016).

LifeComp reconoce la importancia de poder adaptar el estilo de comunicación a diferentes contextos socioculturales, ya que las personas deben ajustar su estilo de comunicación al contexto físico (hora, nivel de ruido, iluminación), así como al contexto cultural, los valores, los estilos de vida, los comportamientos y las creencias del hablante y del interlocutor. Todos ellos influyen en la interpretación que se hace del mensaje. En los entornos multiculturales, cada vez más frecuentes en nuestras sociedades diversas, las personas deben desarrollar una actitud de apertura y respeto por la alteridad cultural (Consejo de Europa 2016), lo que implica la autoconciencia de su propia herencia cultural y su influencia en la forma en que perciben el mundo, incluida la tendencia a interpretarlo desde un punto de vista etnocéntrico (es decir, bajo la creencia frecuente de que la propia cultura es mejor que la de los demás) y la capacidad de cambiar temporalmente la perspectiva propia y de escuchar a los demás con autenticidad (Deardorff, D. K 2013). Además, la relación entre el hablante y la audiencia también establece reglas sobre el nivel de familiaridad y formalidad del intercambio.

Los individuos deben ser conscientes de los diversos sesgos de la comunicación. El más conocido de éstos quizás sea el de confirmación, o tendencia humana a buscar, escuchar y recordar la información que confirma nuestras propias creencias. Ser consciente de este riesgo potencial y tratar de contrastar activamente la información es especialmente útil en los entornos online. Cada vez más, los algoritmos de los buscadores y las plataformas sociales personalizan los resultados de las consultas, ofreciéndolos a medida. Tras el internet de las cosas (Internet of things, IoT) emerge un nuevo paradigma informacional, el internet de los comportamientos (Internet of behaviours, $I o B)$, que usa, por ejemplo, el reconocimiento facial, el rastreo de ubicación 
y los big data, y conecta la información resultante con comportamientos asociados, como compras en efectivo o uso de determinados dispositivos. También debe subrayarse la importancia de desarrollar la capacidad de afirmar las posiciones propias expresando pensamientos, sentimientos, deseos y creencias de manera directa y apropiada, respetando las de los demás. Es decir, con asertividad. Incluimos en la competencia en comunicación destrezas como abogar, promover, discutir, debatir, persuadir y negociar de manera efectiva, tanto en el ámbito personal como público.

Durante la pandemia de la Covid-19, la competencia en comunicación ha sido puesta a una dura prueba. Al no poder relacionarse presencialmente, trabajadores, estudiantes y ciudadanos en general, se han visto abocados al uso intensivo de las tecnologías digitales, suponiendo por un lado un aprendizaje acelerado para la población, pero por otro, un grave problema para aquéllos que no tienen las destrezas ni las capacidades de adquirirlas y para los que no tienen la infraestructura adecuada en sus casas. Ha sido el caso del uso de la videoconferencia, que se ha impuesto como modo alternativo a la comunicación directa. No sólo ha servido al teletrabajo y a la escuela online, sino también a que las familias pudieran estar en contacto (abuelos con nietos, enfermos con familiares, amigos, etc.), que han tenido que aprender a usar estos canales con celeridad inaudita, canales por otro lado considerados pobres por sus limitaciones antes de la pandemia, en particular por la ausencia del contacto físico entre las personas. Es uno de los factores que han dado lugar a la llamada 'fatiga pandémica'.

\section{c Colaboración}

Según LifeComp, para hacer frente a los complejos desafíos de hoy día, se debe fomentar la colaboración efectiva entre individuos, organizaciones y redes. Es posible que la diversidad de perspectivas desempeñe un papel positivo en un contexto de mucha colaboración. En cualquier caso, creemos que las personas necesitan aprender no sólo a hacer frente a la diversidad, sino también a aprovecharla, colaborando y creando sinergias. Los ciudadanos necesitan desarrollar su capacidad para coparticipar en actividades y emprendimientos colectivos y animar a otros a colaborar, utilizando la agenciación colectiva (Bandura, A. 2017) y poniendo en común sus conocimientos, competencias y recursos hacia un objetivo común. El sentido de logro compartido en la colaboración puede ayudar a construir relaciones afectivas y a combatir estados psicológicos como la depresión, la ansiedad, la ira reprimida, el miedo al fracaso, la desesperanza y la pérdida de sentido, lo cual es especialmente relevante en la pandemia de la Covid-19.

Para colaborar de manera efectiva y productiva, LifeComp enfatiza la necesidad de construir una interacción respetuosa con personas que tienen 
afiliaciones culturales, creencias, opiniones o prácticas diferentes a las nuestras. Ello implica sensibilidad hacia las diferentes visiones del mundo y la voluntad de cooperar en relaciones justas. El marco de competencias destaca también la voluntad de contribuir activamente al bien común. La interdependencia positiva, es decir, apoyarse en los esfuerzos de los demás, y la interacción promotora, es decir, alentar y facilitar las contribuciones de los demás, son aspectos clave de la colaboración (Johnson, D. W. y Johnson, R. T. 1989). En la colaboración, son de particular relevancia las actitudes que reconozcan la dignidad, los derechos y las libertades de los demás y las relaciones justas (Consejo de Europa 2016), al tiempo que es clave el nivel de seguridad psicológica $^{12}$ que experimentan los que colaboran (Snowden, D. 2005).

Un sentimiento de confianza unido a una actitud de respeto dentro del grupo es fundamental para el aprendizaje en los equipos de trabajo, ya que permite a los integrantes buscar retroalimentación y más información, hablar sobre los errores e innovar, facilitando así acciones adecuadas para el cumplimiento de una tarea (Duhigg, C. 2016). En muchos entornos colaborativos en los que participan personas con diferentes puntos de vista o experiencia, es imprescindible aprender a manejar los conflictos, a prevenirlos y a transformar las disputas en energía colaboradora. Los conflictos son parte de las relaciones humanas y pueden ocurrir en todos los ámbitos de la vida, por lo que es importante que los ciudadanos aprendan a gestionarlos de forma eficaz y constructiva. Para la gestión de conflictos es necesario recopilar e intercambiar información para identificar problemas subyacentes, buscar alternativas, evaluar sus implicaciones y estar abierto ante la preferencia que podamos tener en la selección de soluciones (Bacon, N. y Blyton, P. 2007). Las estrategias para poner fin al conflicto incluyen la negociación, la mediación, la conciliación y el arbitraje (Rahim, M. A. 2002).

Cuando los miembros del equipo tienen roles, planes y objetivos claros, la dinámica de trabajo mejora y el equipo en su conjunto obtiene mejores resultados (Duhigg, C. 2016). Una inteligencia colectiva surge de la colaboración en grupo, pudiéndose aprovechar su poder para resolver problemas o alcanzar metas. La inteligencia colectiva se correlaciona fuertemente con la empatía promedio de los miembros del grupo que colabora, lo que indica que cuanto mayor sea la capacidad de los miembros del grupo para comprender los sentimientos y perspectivas de los demás, mayor será la inteligencia colectiva del grupo y su capacidad para realizar tareas con éxito (Sala, A., Punie, Y., Garkov, V. y Cabrera Giraldez, M. 2020). Evitar que unas pocas personas dominen el proceso de comunicación también es muy beneficioso,

${ }^{12}$ La seguridad psicológica es la sensación de que los miembros de un grupo no descuidan, desprecian o socavan a alguien por expresar opiniones, pedir aclaraciones o proponer soluciones. 
al alentar a los miembros del grupo a sentirse autorizados a expresar sus propias opiniones, incluso cuando van en contra de lo que se ha sido decidido colectivamente. La peligrosa paradoja de Abilene $^{13}$ se puede evitar así (Harvey, J. B. 1974).

LifeComp enfatiza la necesidad de adoptar un enfoque sistémico, es decir, manejar el trabajo en equipo con un punto de vista global para combinar a la perfección conciencia y acción. Tal enfoque requiere que comprendamos cómo los aspectos diferentes e interconectados de una tarea de grupo, así como los factores externos, influyen en sus resultados de la colaboración. Implica centrarse en las relaciones dinámicas, complejas y cambiantes entre los componentes, y en cómo contribuir a la estabilidad del sistema. En otras palabras, tenemos que adoptar una perspectiva que nos permita ver cómo la tarea encaja en el contexto más amplio. Para que una colaboración exitosa, el grupo necesita aprovechar las diferentes capacidades y complementariedades de sus miembros, de modo que todos puedan contribuir con sus habilidades, conocimientos y actitudes a los resultados del trabajo.

Durante la pandemia de la Covid-19 la colaboración en los contextos de trabajo y de estudio han sido esenciales. Se podría hablar de un espíritu de colaboración renaciente ante la competición, a veces desmedida, que caracteriza nuestras sociedades liberales. Naturalmente han ocurrido conflictos en los trabajos, entre los estudiantes y en otros contextos sociales, incluso de manera más exacerbada que en tiempos de normalidad. No obstante, los individuos han expresado un alto deseo de colaborar y se han puesto a ello. En el caso de los estudiantes, acuciados por la situación, se han producido numerosos grupos de colaboración mediados por las redes sociales y las tecnologías digitales. En las familias, se ha atendido colaborativamente a los vulnerables. E incluso, tras los desastres de las residencias para personas mayores, se manifiesta una tendencia en las familias a hacerse cargo de éstas, aunque esta tendencia pueda ser temporal.

\section{Aprender a aprender: el pensamiento crítico}

'Aprender a aprender' la capacidad de perseguir y persistir en el aprendizaje y de organizarlo, incluyendo la gestión eficaz del tiempo y la información, tanto a escala individual como grupal (Parlamento Europeo y Consejo Europeo 2006). Esta área de LifeComp comprende en realidad tres competencias: Mentalidad de crecimiento, Pensamiento crítico y Gestión del

${ }^{13}$ La paradoja de Abilene se da cuando los individuos de un grupo apoyan una decisión, incluso si esto es contrario a su preferencia, para ajustarse a lo que creen que es el consenso del grupo. 
aprendizaje. Nos detenemos únicamente en la segunda, ya que las otras dos nos parecen igualmente relevantes antes y durante la pandemia.

\section{a Pensamiento crítico}

El pensamiento crítico es una habilidad cognitiva de orden superior crucial para hacer frente a la incertidumbre, la complejidad y el cambio. De ahí que la destaquemos en el contexto de la pandemia Covid-19 y la postpandemia. El pensamiento crítico implica hacer análisis hábiles y autodirigidos de la información, las creencias o el conocimiento adquirido, con una reconstrucción continua del pensamiento (Paul, R. W. y Elder, L. 2002), y sabiendo sobre los métodos para evaluar y producir nuevos conocimientos y estrategias para resolver problemas. Supone igualmente tener conciencia de las tendencias egocéntricas y sociocéntricas del pensamiento humano, que pueden ser nocivas para la calidad del razonamiento y la evaluación de la información. Los pensadores críticos se esfuerzan por desarrollar virtudes intelectuales como la integridad intelectual para reconocer áreas de inconsistencia y contradicción en el pensamiento propio, la humildad intelectual para reconocer posibles errores, y la empatía intelectual para hacer esfuerzos sinceros por comprender la perspectiva de los demás. Por consiguiente, el pensamiento crítico implica la conciencia de que los valores personales influyen en el proceso de comparar, evaluar y ponderar diferentes argumentos (Veugelers W., de Groot, I., Stolk, V. 2017).

La cantidad de información en la era de la 'posverdad', en la que los hechos objetivos influyen menos en la formación de la opinión pública que las apelaciones a las emociones y creencias personales, es casi ilimitada. Por ello, LifeComp subraya que es fundamental que los ciudadanos puedan distinguir entre hechos reales, propaganda, opiniones y rumores, y que se comprometan a detener la difusión de información errónea, invirtiendo la tendencia que hace que las noticias falsas online se difundan más lejos, más rápidamente, más profundamente y más en general que la verdad (Vosoughi, S., Roy, D. y Aral, S. 2018). En este año y medio que dura ya la pandemia de la Covid-19 hemos sido testigos de la importancia de ser ciudadanos pensadores críticos ante el alud de desinformación, a veces provenientes de círculos gubernamentales populistas. Ha sido el caso de gobernantes que, haciendo caso omiso de la evidencia científica, han pregonado la relativa inocuidad del virus SARS-CoV-2 y de movimientos ciudadanos alentado las teorías conspiratorias y la inconveniencia de vacunarse.

Los ciudadanos tienen todo el interés en devenir pensadores críticos. En unos tiempos en que la información online puede carecer de guardianes, es importante que las personas sean conscientes de la posibilidad de lidiar con la información errónea y estén dispuestas a verificar los datos y evaluar la 
credibilidad de su fuente, su exactitud, fiabilidad y autoridad, prefiriendo a las fuentes primarias de información sobre las fuentes secundarias cuando sea posible. LifeComp enfatiza la relevancia de dar sentido a los datos más que a acumularlos, lo que requiere una mentalidad abierta y crítica. Los pensadores críticos necesitan valorar situaciones y suposiciones, hacer preguntas y evaluar si un argumento tiene sentido o no (UNICEF 2017).

Finalmente, cabe hablar de la capacidad de pensar con creatividad en la resolución de problemas. La postpandemia traerá una crisis económica, social y de salud mental. La creatividad, una habilidad que las personas pueden desarrollar para generar resultados originales y valiosos, será el motor de la de innovación necesaria para transformar la economía hacia un paradigma verde y para resolver los múltiples problemas que nos acechan, como la pérdida masiva de empleo y la precariedad, sobre todo en la población joven. Para desarrollar la creatividad, los individuos necesitan usar su imaginación e intuición, adoptando una actitud lúdica para explorar nuevas ideas y evaluar nuevas estrategias de resolución de problemas mientras aceptan algunos niveles de asunción de riesgos (Deakin Crick, y otros 2015). Ser persistente, colaborador y disciplinado son «hábitos mentales» nutritivos que sustentan la creatividad (Lucas, B. 2016). Confiemos en que la inteligencia colectiva se alíe con la creatividad humana para salir airosos de la crisis global que vimos.

\section{CONCLUSIONES}

El marco conceptual europeo para la Competencia clave 'Personal, social y de Aprender a aprender', LifeComp, fue publicado en junio de 2020. La elaboración del marco fue llevada a cabo por la Comisión Europea con la ayuda de numerosos expertos y responde a la Recomendación de 2018 del Consejo de la Unión Europea sobre Competencias clave para el aprendizaje permanente, cuyo objetivo es que los ciudadanos tengan el conjunto de competencias necesarias para su desarrollo personal, la inclusión social, la ciudadanía activa y el trabajo. La Recomendación, que señala su respeto por los principios de subsidiariedad y proporcionalidad que se aplican en el ámbito de la Educación, propone además reforzar la adquisición de competencias ciudadanas para concienciar sobre valores comunes, ya que éstos forman la base del desarrollo personal y social. Sigue así en la línea de otros actos legislativos como el Pilar europeo de derechos sociales, que establece que para que los ciudadanos tengan una educación, una formación y un aprendizaje permanente inclusivos y de calidad, deben adquirir las capacidades que les permitan participar plenamente en la sociedad, gestionar sus transiciones laborales, y mejorar su empleabilidad. La promoción de las competencias clave constituye igualmente uno de los objetivos del Espacio Europeo de 
Educación. Entre las competencias de LifeComp se encuentran la Autorregulación, la Flexibilidad y el Bienestar. Los ciudadanos con estas competencias han podido ser más resilientes durante la crisis sanitaria de la Covid-19, lo que sugiere la conveniencia de seguir desarrollándolas a través de la educación. Lo mismo sucede con las competencias sociales Empatía, Comunicación y Colaboración, de particular interés en las esferas laboral y educativa. El pensamiento crítico es crucial en un contexto caracterizado por la desinformación y la profusión de noticias falsas y teorías conspirativas. LifeComp puede servir como base para educadores, trabajadores y ciudadanos en general, especialmente en contextos de complejidad e incertidumbre como el que vivimos.

\section{VI.REFERENCIAS}

AbTahi, Y., Graven, M., y LeRman, S. 2017. «Conceptualising the more knowledgeable other within a multi-directional ZPD.» Educational Studies in Mathematics (96): 275-287. doi:https://doi.org/10.1007/s10649-017-9768-1.

Aoun, J. 2017. Robot-Proof. Higher Education in the Age of Artificial Intelligence. Cambridge: MIT University Press Group Ltd.

Bacigalupo, M., Kampylis, P., Punie, Y., y Van den Brande, G. 2016. EntreComp: The Entrepreneurship Competence Framework. Joint Research Centre European Commission, Luxemburgo: Publications Office of the European Union. https://publications.jrc.ec.europa.eu/repository/handle/JRC101581.

BACON, N. y BLYTON, P. 2007. «Conflict for Mutual Gains? Journal of Management Studies.» 814-834. doi:https://doi.org/10.1111/j.1467-6486.2006.00668.x.

BAndurA, A. 2017. «Toward a Psychology of Human Agency: Pathways and Reflections.» Perspectives on Psychological Science 13 (2): 130-136. doi:https://doi. org/10.1177/1745691617699280.

Baumeister, R. F. y Heatherton, T. F. 1996. «Self-Regulation Failure: An Overview.»Psychological Inquiry 7 (1): 1-15. doi:https://doi.org/10.1207/ s15327965pli0701_1.

Belfield, C., Bowden, A. B., Klapp, A., Levin, H., Shand, R., y Zander, S. 2015. «The Economic Value of Social and Emotional Learning.» Journal of BenefitCost Analysis 6 (3): 508-544. https://doi.org/10.1017/bca.2015.55.

BENNETT, N., y Lemoine, G. J. 2014. «What a difference a word makes: Understanding threats to performance in a VUCA world.» Business Horizons 57 (3): 311317. doi:https://doi.org/10.2139/ssrn.2406676.

BRonfenBRenNER, U. 1979. The Ecology of Human Development: Experiments by Nature and Design. Cambridge, Massachusetts: Harvard University Press.

CABrera, M. y Malanowski, N. (eds). 2009. Information and Communication Technologies for Active Ageing. Opportunities and Challenges for the European Union. Amsterdam: IOS Press.

Camara, W., O'Connor, R., Mattern, K., y Hanson, M. A. 2015. «Beyond Academics: A Holistic Framework for Enhancing Education and Workplace Suc- 
cess.» ACT. http://www.act.org/content/dam/act/unsecured/documents/ACT_ RR2015-4.pdf.

CAÑAs, J. J., Quesada, J. F., Antolí, A. y FaJARdo, I. 2003. «Cognitive flexibility and adaptability to environmental changes in dynamic complex problem-solving tasks.» Ergonomics 482-501. doi:https://doi.org/10.1080/0014013031000061640.

Cavallini, E., Bianco, F., Bottiroli, S., Rosi, A., Vecchi, T., y Lecce, S. 2015. «Training for generalization in Theory of Mind: a study with older adults.» Frontiers in Psychology 1-9. doi:https://doi.org/10.3389/fpsyg.2015.01123.

CEDEFOP. 2019. «Skills-OVATE: Skills Online Vacancy Analysis Tool for Europe.»https://www.cedefop.europa.eu/en/data-visualisations/skills-online-vacancies/skills-occupations.

Cefai, C., Bartolo, P. A., Cavioni, V, Downes, P. 2018. Strengthening Social and Emotional Education as a core curricular area across the EU. A review of the international evidence, NESET II report. Luxemburgo: Publications Office of the European Union, doi: 10.2766/664439. doi:10.2766/664439.

COMISIÓN EUROPEA. 2018. «Commission Staff Working Document Accompanying the document Proposal for a COUNCIL RECOMMENDATION on Key Competences for LifeLong Learning $\{\mathrm{COM}(2018) 24$ final\}.» Eur-Lex. https://eur-lex. europa.eu/legal-content/EN/TXT/HTML/?uri=CELEX:52018SC0014\&from= EN.

2017. «Comunicacion de la Comisión al Parlamento Europeo, al Consejo, al Comité Económico y Social Europeo y al Comité de las Regiones: Reforzar la identidad europea mediante la Educación y la Cultura.» EUR-Lex: El portal de Derecho europeo. https://eur-lex.europa.eu/legal-content/ES/TXT/HTML/?uri= CELEX:52017DC0673\&from=EN.

— 2017. «Comunicación de la Comisión al Parlamento Europeo, al Consejo, al Comité Económico y Social Europeo, y al Comité de las Regiones: Establecimiento de un pilar europeo de derechos sociales.» EUR-Lex: Portal del Derecho Europeo. https://eur-lex.europa.eu/legal-content/ES/TXT/PDF/?uri=CELEX:52 017DC0250\&from $=\mathrm{EN}$.

2018. Key competences for lifelong learning. Luxemburgo: Official Journal of the European Union. https://eur-lex.europa.eu/legal-content/EN/TXT/PDF/?uri= CELEX:32018H0604(01)\&from=EN.

2018. «La lucha contra la desinformación en línea: un enfoque europeo. Comunicación de la Comisión $\operatorname{COM(2018)} 236$ final.» https://eur-lex.europa.eu/legalcontent/ES/TXT/PDF/?uri=CELEX:52018DC0236\&from=EN.

Comisión Europea y Alto Representante de la Unión Europea Para Asuntos EXTERIORES Y Política DE SEgURIDAD Común. 2020. «La lucha contra la desinformación acerca de la COVID-19: contrastando los datos.» Junio. https://eur-lex.europa.eu/legal-content/ES/TXT/PDF/?uri=CELEX:52020JC0008\&from=EN.

CONSEJO DE EUROPA. 2016. Competences for democratic culture. Living togheter as equals in culturally diverse democratic societies. Council of Europe Publishing. https://rm.coe.int/16806ccc07.

— 2018. Reference framework of Competences for Democratic Culture. Estrasburgo: Consejo de Europa. https://www.coe.int/en/web/campaign-free-to-speaksafe-to-learn/reference-framework-of-competences-for-democratic-culture. 
Deakin Crick, R., S. Huang, A., Ahmed Shafi, y C. Goldspink. 2015. «Developing Resilient Agency in Learning: The Internal Structure of Learning Power.» British Journal of Educational Studies 63 (2): 121-160.

DEARDORFF, D. K. 2013. Promoting understanding and development of intercultural dialogue and peace: a comparative analysis and global perspective of regional studies on intercultural competence. París: UNESCO.

Delors, J. 1996. «Learning: The Treasure Within.» París.

Derntl, B. y Regenbogen, C. 2014. «Empathy.» En Social Cognition and Metacognition in Schizophrenia. Psychopathology and Treatment Approaches, de Dimaggio, G., Brüne, M. (Ed.) P.H. Lysaker, 69-81. London: Elsevier.

Donlevy, V., van Driel, B., Horeau McGrath, C. 2019. «Education as self-fulfilment and self-satisfaction,European Commission, Seville, 2019, JRC117548.» Seville.

DuHigG, C. 2016. «What Google Learned From Its Quest to Build the Perfect Team.» The New York Times Magazine. https://www.nytimes.com/2016/02/28/ magazine/what-google-learned-from-its-quest-to-build-the-perfect-team.html.

— 2016. «What Google Learned From Its Quest to Build the Perfect Team.» The New York Times Magazine. https:/www.nytimes.com/2016/02/28/magazine/ what-google-learned-from-its-quest-to-build-the-perfect-team.html.

Durlak, J. A., Weissberg, R. P., Dymnicki, A. B., TAylor, R. D. Schellinger, K. B. 2011. «The impact of enhancing students' social and emotional learning: A meta-analysis of school-based universal interventions.» Child Development 82: 405-432.

Ekman, P., Sorenson, E. y Friesen, W. 1969. «Pan-cultural elements in facial displays of emotion.» Science 164: 86-88. doi:https://doi.org/10.1126/science.164.3875.86.

EPSC, European Commission. 2017. 10 trends transforming education as we know it. Luxemburgo: Publications Office of the EU. https:/op.europa.eu/en/publication-detail/-/publication/227c6186-10d0-11 ea-8c1f-01aa75ed71a1/language-en.

EPSC. Comision Europea. 2019. 10 trends shaping the future of work. Luxemburgo: Publications Office of the EU. https://ec.europa.eu/epsc/sites/epsc/files/10trends_future-of-work.pdf.

European Lifelong Guidance Policy Network. 2015. «Guidelines for Policies and Systems Development for Lifelong Guidance. A Reference Framework for the EU and for the Commission.» Finnish Institute for Educational Research. http://www.elgpn.eu/publications/browse-by-language/english/elgpn-tools-no6-guidelines-for-policies-and-systems-development-for-lifelong-guidance/.

Gonzalez Vazquez, I., Milasi, S., Carretero Gomez, S., Napierala, J., Robledo Bottcher, N., Jonkers, K., Goenaga, X. (eds.), Arregui Pabollet, E., BaciGAlupo, M., Biagi, F., CABrera Giraldez, M.,... 2019. The changing nature of work and skills in the digital age. Luxemburgo: Publications Office of the European Union. doi:http://dx.doi.org/10.2760/679150.

HARVEY, J. B. 1974. «The abilene paradox: The management of agreement.» Organizational Dynamics 3 (1). doi:https://doi.org/10.1016/0090-2616(74)90005-9.

Johnson, D. W. y Johnson, R. T. 1989. Cooperation and competition: Theory and research. Edina, MN: Interaction Book Company. 
Johnson, D. W. y Johnson, R. T. 2005. «New developments in social interdependence theory.» Genetic, Social, and General Psychology Monographs 13 (4): 285-358. https://doi.org/10.3200/MONO.131.4.285-358.

Koole, S. 2009. «The psychology of emotion regulation: An integrative review.» Cognition \& Emotion 23 (1): 4-41. doi:https://doi. org/10.1080/02699930802619031.

Kremer, J., y Dietzen, L. 1991. «Two Approaches to Teaching Accurate Empathy to Undergraduates: Teacher-Intensive and Self-Directed.» Journal of College Student Development 32 (1): 69-75.

LuCAS, B. 2016. «A Five-Dimensional Model of Creativity and its Assessment in Schools.» Applied Measurement In Education 29 (4): 278-290. doi:https://doi.or g/10.1080/08957347.2016.1209206.

Luthans, F., Avolio, B., Avey, J. B., y Norman, S. M. 2007. «Positive psychological capital: Measurement and relationship with performance and satisfaction.» Personnel psychology 60 (3): 541-572. doi:https://doi. org/10.1111/j.1744-6570.2007.00083.x.

Ministros de EdUCACión DE LA UE. 2015. «Declaration on Promoting citizenship and the common values of freedom, tolerance and non-discrimination through education.» https://ec.europa.eu/assets/eac/education/news/2015/documents/citizenship-education-declaration_en.pdf.

MoILANEN, K. L. 2007. «The Adolescent Self-Regulatory Inventory: The Development and Validation of a Questionnaire of Short-Term and Long-Term Self-Regulation.» Journal of Youth Adolescence 835-848. doi:https://doi.org/10.1007/ s10964-006-9107-9.

NACIONES UnidAs. 2015. «Resolution adopted by the General Assembly on 25 September 2015. Transforming our world: the 2030 Agenda for Sustainable Development. (A/RES/70/1).»https://www.un.org/ga/search/view_doc.asp?symbol=A/ RES/70/1\&Lang=E.

OMS. 2020. «Coronavirus disease 2019 (COVID-19). Situation Report 445.» https:// www.who.int/docs/default-source/coronaviruse/situation-reports/20200305-sitrep-45-covid-19.pdf?sfvrsn=ed2ba78b_4.

OXFord LEARNER's Dictionaries. 2016. Oxford Learner's Dictionaries.

PARISER, E. 2011. The Filter Bubble: How the New Personalized Web Is Changing What We Read and How We Think. Penguin.

Parlamento Europeo y ConSEJo Europeo. 2006. «Recommendation of the European Parliament and of the Council on key competences for lifelong learning.» Official Journal of the European Union. https://eur-lex.europa.eu/L.

PAul, R. W. y Elder, L. 2002. Critical Thinking: Tools for Taking Charge of Your Professional and Personal life. New Jersey: Financial Times Prentice Hall.

RAHIM, M. A. 2002. "Towards a theory of managing organizational conflict.» The International Journal of Conflict Management (13) 3: 206-235. doi:https://doi. org/10.2139/ssrn.437684.

RIESS, H. 2017. «The Science of Empathy.» Journal of Patient Experience 4 (2): 7477. https://doi.org/10.1177/2374373517699267. 
RÖSNER, L. y KRÄMER, N. 2016. «Verbal Venting in the Social Web: Effects of Anonymity and Group Norms on Aggressive Language Use in Online Comments.» Social Media + Society 1-13. https://doi.org.10.1177/2056305116664220.

Sala, A., Punie, Y., Garkov, V. y Cabrera Giraldez, M. 2020. LifeComp: The European Framework for Personal, Social and Learning to Learn Key Competence. Luxembourg: Publications Office of the European Union. doi:10.2760/302967, JRC120911.

SNOwden, D. 2005. «Complex Acts of Knowing: Paradox and Descriptive SelfAwareness.» Bulletin of the American Society for Information Science and Technology 29 (4): 23-28. https://doi.org/10.1002/bult.284.

StringHeR, C. 2014. What is learning to learn? A learning to learn process and output model. In Ruth Deakin Crick, Cristina Stringher, \& Kai Ren (Eds.), Learning to Learn: International perspectives from theory and practice. New York: Routledge.

Treffinger, D., Young, G., Selby, E. y Shepardson, C. 2002. Assessing Creativity: A Guide for Educators. The National Research Center on the Gifted and Talented. https://files.eric.ed.gov/fulltext/ED505548.pdf.

UE. 2000. «Carta de los Derechos Fundamentales de la Unión Europea.» europarl. europa.eu. https://www.europarl.europa.eu/charter/pdf/text_es.pdf.

2012. «Versiones consolidadas del Tratado de la Unión Europea y del Tratado de Funcionamiento de la Unión Europea.» Editado por Diario Oficial de Unión Europea. http://eur-1ex.europa.eu/legal-content/ES/ TXT/?uri=celex\%3A12012M\%2FTXT.

UNICEF. 2017. Reimagining Life Skills and Citizenship Education in the Middle East and North Africa. A Four-Dimensional and Systems Approach to 21st Century Skills. Conceptual and Programmatic Framework. UNICEF. https://www. unicef.org/mena/media/6151/file/LSCE\%20Conceptual\%20and\%20Programmatic\%20Framework_EN.pdf\%20.pdf.

Veugelers, W., DE Groōt, I., Stolk, V. 2017. Research for CULT Committee Teaching Common Values in Europe, European Parliament, Policy Department for Structural and Cohesion Policies. European Parliament.

Vosoughi, S., RoY, D. y ArAL, S. 2018. «The spread of true and false news online.» Science (359): 1146-1151. doi:https://doi.org/10.1126/science.aap9559.

VYGOTSKY, L. S. 1997. «The History of the development of higher mental functions.» (Plenum Press) 4.

Watzlawick, P., Helmick Beavin, J. y Jackson, D. 1967. Pragmatics of Human Communication. A study of interactional patterns, pathologies and paradoxes. W. W. Norton \& Company. 


\title{
LIFECOMP: EL MARCO DE REFERENCIA EUROPEO PARA LA COMPETENCIA PERSONAL, SOCIAL Y DE APRENDER A APRENDER. RELEVANCIA EN EL CONTEXTO DE LA COVID-19
}

\author{
Lifecomp: The european framework for the key competence \\ personal, social and learning to learn. Relevance in the \\ COVID-19 context
}

\author{
Marcelino Cabrera Giráldez \\ Investigador del Centro Común de Investigaciones de la Comisión Europea \\ Doctorando del Programa Unión Europea de la UNED \\ Arianna Sala \\ Investigadora del Centro Común de Investigaciones de la Comisión Europea
}

http://dx.doi.org/10.18543/ed-69(1)-2021pp155-186

\section{Copyright}

Estudios de Deusto es una revista de acceso abierto, lo que significa que es de libre acceso en su integridad. Se permite su lectura, la búsqueda, descarga, distribución y reutilización legal en cualquier tipo de soporte sólo para fines no comerciales, sin la previa autorización del editor o el autor, siempre que la obra original sea debidamente citada y cualquier cambio en el original esté claramente indicado

Estudios de Deusto is an Open Access journal which means that it is free for full access, reading, search, download, distribution, and lawful reuse in any medium only for non-commercial purposes, without prior permission from the Publisher or the author; provided the original work is properly cited and any changes to the original are clearly indicated. 